\title{
Effect of sarcopenia on short- and long- term outcomes in patients with gastric neuroendocrine neoplasms after radical gastrectomy: results from a large, two- institution series
}

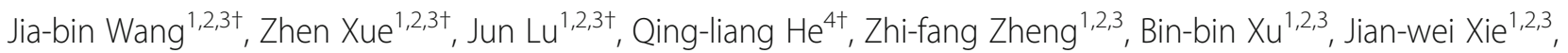
Ping Li $i^{1,2,3}, Y u X^{5}$, Jian-xian Lin 1,2,3, Qi-yue Chen ${ }^{1,2,3}$, Long-long CaO ${ }^{1,2,3}$, Mi Lin ${ }^{1,2,3}$, Ru-hong Tư ${ }^{1,2,3}$, Ze-ning Huang ${ }^{1,2,3}$, Ju-li Lin ${ }^{1,2,3}$, Chang-ming Huang ${ }^{1,2,3}$ and Chao-hui Zheng ${ }^{1,2,3^{*}}$

\begin{abstract}
Background: The relationship between sarcopenia and the prognoses of patients with gastric neuroendocrine neoplasms ( $g$-NENs) is unclear. This study was designed to explore the effects of sarcopenia on short-term and long-term outcomes of patients with g-NENs after radical gastrectomy.

Methods: This study retrospectively collected data from 138 patients with g-NENs after radical gastrectomy. The skeletal muscle index (SMI) diagnostic threshold for sarcopenia was determined using X-tile software. Cox regression analyses were performed to determine the independent risk factors for 3-year overall survival (OS) and 3year recurrence-free survival (RFS).

(Continued on next page)
\end{abstract}

\footnotetext{
*Correspondence: wwkzch@163.com

${ }^{+}$Jia-bin Wang, Zhen Xue, Jun Lu and Qing-liang should be considered cofirst authors.

'Department of Gastric Surgery, Fujian Medical University Union Hospital, No.29 Xinquan Road, Fuzhou 350001, Fujian Province, China

Department of General Surgery, Fujian Medical University Union Hospital, Fuzhou, China

Full list of author information is available at the end of the article
}

(c) The Author(s). 2020 Open Access This article is licensed under a Creative Commons Attribution 4.0 International License, which permits use, sharing, adaptation, distribution and reproduction in any medium or format, as long as you give appropriate credit to the original author(s) and the source, provide a link to the Creative Commons licence, and indicate if changes were made. The images or other third party material in this article are included in the article's Creative Commons licence, unless indicated otherwise in a credit line to the material. If material is not included in the article's Creative Commons licence and your intended use is not permitted by statutory regulation or exceeds the permitted use, you will need to obtain permission directly from the copyright holder. To view a copy of this licence, visit http./creativecommons.org/licenses/by/4.0/. The Creative Commons Public Domain Dedication waiver (http://creativecommons.org/publicdomain/zero/1.0/) applies to the data made available in this article, unless otherwise stated in a credit line to the data. 
(Continued from previous page)

Results: In this study, 59 patients (42.8\%) were diagnosed with sarcopenia. Among patients in the sarcopenia group and nonsarcopenia group, the incidences of total postoperative complications were 33.9 and $30.4 \%$, incidences of serious postoperative complications were 0 and $3.7 \%$, incidences of postoperative surgical complications were 13.6 and 15.2\%, and incidences of postoperative systemic complications were 20.3 and $15.2 \%$, respectively (all $p>0.05$ ). The 3 -year OS and RFS rates were significantly worse in the sarcopenia group than in the nonsarcopenia group (OS: $42.37 \%$ vs $65.82 \%, p=0.004$; RFS: $52.54 \%$ vs $68.35 \%, p=0.036$ ). The multivariate analysis revealed a relation between sarcopenia and the long-term prognoses of patients with g-NENs. A stratified analysis based on the pathological type revealed that the Kaplan-Meier curve was only significantly different in patients with gastric mixed adenoneuroendocrine carcinoma (gMANEC) (OS: 40.00\% vs 71.79\%, $p=0.007$; RFS: 51.43\% vs 74.36\%, $p=0.026$ ); furthermore, the multivariate analysis identified sarcopenia as an independent risk factor for patients with gMANEC $(p<0.05)$.

Conclusions: Sarcopenia is not related to the short-term prognoses of patients with g-NENs. Sarcopenia is an independent risk factor for patients with gMANEC after radical surgery.

Keywords: Gastric neuroendocrine neoplasms, Sarcopenia, Overall survival, Risk factors

\section{Synopsis}

This study was designed to explore the effects of sarcopenia on the short-term and long-term outcomes of patients with g-NENs after radical gastrectomy by using data from two independent large-volume institutions.

\section{Background}

Gastric neuroendocrine neoplasms (g-NENs) are a class of tumors with significant heterogeneity that account for approximately $4 \%$ of all neuroendocrine tumors [1], and their incidence is gradually increasing $[2,3]$. g-NENs include three categories: gastric neuroendocrine tumor (gNET), gastric neuroendocrine carcinoma (gNEC) and gastric mixed adenoneuroendocrine carcinoma (gMANEC) [4]. Surgery is the main treatment for gNET, gNEC, gMANEC [5]. Because of its different clinicopathological features, the understanding and the prognostic factors of g-NENs are still rarely studied [6-9]. Therefore, studies exploring the factors influencing the shortterm and long-term outcomes of patients with g-NENs after radical surgery are important to improve the prognosis of these patients.

In recent years, sarcopenia has been reported to be closely related to the prognosis of patients with gastric cancer, liver cancer, colorectal cancer, and other malignant tumors [10-16]. However, no studies have reported the effect of sarcopenia on the short-term and long-term postoperative outcomes of patients with g-NENs.

This study retrospectively analyzed the clinicopathological data from 138 patients with g-NENs treated at two institutions, with the aim of exploring the effect of sarcopenia on the short-term and long-term outcomes of patients with g-NENs after radical gastrectomy.

\section{Methods \\ Patient selection}

The clinicopathological data from patients diagnosed with g-NENs at the Fujian Medical University Union Hospital (FMUUH) and the First Affiliated Hospital of Fujian Medical University (FMUFAH) from December 2009 to December 2015 were retrospectively analyzed. The inclusion criteria were as follows: (1) patients who were diagnosed with g-NENs by pathology; (2) patients without distant metastasis, as assessed by a preoperative examination; and (3) patients who underwent R0 excision. The following exclusion criteria were used: (1) distant metastasis was identified preoperatively and intraoperatively; (2) patients received neoadjuvant chemotherapy or radiotherapy before surgery; and (3) basic clinical data and computed tomography (CT) images were incomplete. One hundred thirty-eight patients with g-NENs were finally included in this study (111 patients at FMUUH and 27 patients at FMUFAH, Supplementary Table 1). The tumor size, location, $\mathrm{T}$ stage and $\mathrm{N}$ stage were comprehensively determined by two attending physicians according to the findings of gastroscopy, abdominal CT and other auxiliary examinations performed preoperatively. The type of surgical resection performed was determined by the location of the tumor. Lymph node dissection was performed according to the Japanese gastric cancer treatment guidelines (13th edition) [17]. For patients with gNET, somatostain was recommended. For patients with stage II or higher gNEC or gMANEC, fluorine-based postoperative adjuvant chemotherapy was recommended [18]. The study was approved by the Ethics Committees of FMUUH and FMUFAH. 


\section{Diagnosis and classification of g-NENs}

According to the $2010 \mathrm{WHO}$ classification of tumors of the digestive system [4], g-NENs were classified as gNET, including NET1 and NET2 grades; gNEC, including large-cell carcinomas and small-cell carcinomas; and gMANEC. Neuroendocrine cells were confirmed, diagnosed and classified based on the microscopic histomorphological features and immunohistochemical staining for neuroendocrine tumor-related biomarkers (such as CgA, CD56 and Syn). The pathological findings were confirmed by two experienced pathologists.

\section{Analysis of $\mathrm{CT}$ images}

A preoperative abdominal CT scan within 1 month of surgery was considered to accurately reflect the patient's muscle status. A researcher who was blinded to the outcome measured the skeletal muscle cross-sectional area $\left(\mathrm{cm}^{2}\right)$ at the level of the third lumbar vertebra (L3) by using Osirix 3.3 software (32-bit; http://www.osirixviewer.com) [19]. The researcher was trained to accurately identify lumbar vertebrae and muscles (Supplementary Fig. 1). The average surface area $\left(\mathrm{cm}^{2}\right)$ of two consecutive slices was used for analysis. If necessary, the area of the selected area was manually adjusted to accurately calculate the area. The tissue discrimination threshold of skeletal muscle is -29 to +150 Hounsfield units (HUs) [20]. The muscle area $\left(\mathrm{cm}^{2}\right)$ was standardized to the height $\left(\mathrm{m}^{2}\right)$ to obtain the L3 skeletal muscle index (SMI) $\left(\mathrm{cm}^{2} / \mathrm{m}^{2}\right)[21]$.

\section{Optimal SMI cutoff value and definition of sarcopenia}

Separate X-tile plots were constructed for men and women. For the men, when the SMI value was $44.3 \mathrm{~cm}^{2}$ / $\mathrm{m}^{2}$, the maximum chi-square log-rank value of 4.2611 was achieved. Therefore, a $\mathrm{SMI} \leq 44.3 \mathrm{~cm}^{2} / \mathrm{m}^{2}$ was defined as sarcopenia, and a $\mathrm{SMI}>44.3 \mathrm{~cm}^{2} / \mathrm{m}^{2}$ was defined as nonsarcopenia $(p=0.038)$ (Supplementary Fig. 2).

For the women, a $\mathrm{SMI} \leq 32.4 \mathrm{~cm}^{2} / \mathrm{m}^{2}$ was defined as sarcopenia in the same manner $\left(x^{2}=1.0039, p=0.214\right)$ (Supplementary Fig. 2).

\section{Variables and definitions}

Overall survival (OS) was defined as the time from surgery to the last follow-up, death, or the last record in the follow-up database (such as loss of follow-up or death from other diseases). Recurrence-free survival (RFS) was defined as the time from surgery to the initial recurrence. Postoperative complications were classified according to the Clavien-Dindo criteria [22]. Total postoperative complications were defined as Clavien-Dindo grade 2 and higher. Severe complications were defined as Clavien-Dindo grade 3 and higher [11]. Postoperative surgical complications were defined as complications related to the surgical procedure. Systemic complications were defined as complications that were not directly related to the surgical field or the incision. For Ki-67, 60\% positive was considered the cut-off point. The ASA physical status classification system was used in this research [18, 23]. ASA I, patient is healthy with no systemic disease; ASA II, patient has mild systemic disease; ASA III, patient has severe systemic disease or multiple diseases affecting different organ systems; ASA IV, patient has severe systemic disease that is a constant threat to life; ASA V, patient is moribund and not expected to survive without the operation; and ASA VI, brain dead patient whose organs are being removed for donation $[24,25]$.

\section{Follow-up}

The median follow-up time was 36 months (range: 1102 months). Physical and laboratory examinations were performed regularly after surgery, once every 3 months for 2 years, every 6 months for the next 3 years, and once a year after 5 years. In addition, imaging examinations, including chest radiographs, abdominal and pelvic CTs, and endoscopy, were performed at least once a year. If necessary, additional MRI or PET studies were performed to determine whether recurrence was present.

\section{Statistical analysis}

All data were statistically analyzed using SPSS 22.0 software. Continuous variables are reported as the means \pm $\mathrm{SD}$ or medians (interquartile ranges). X-tile plots were used as a new bioinformatics tool for biomarker assessments and outcome-based cutoff point optimization [10, 26]. Categorical and continuous variables were compared using a $x^{2}$ test or Fisher's exact test and a t-test, respectively. The OS and RFS rates were calculated by the Kaplan-Meier method, and the differences were assessed with log-rank tests. The Cox proportional hazards regression model was used to analyze the independent prognostic factors for 3-year OS and RFS rates. $P$ values less than 0.05 were considered statistically significant.

\section{Results}

\section{Clinicopathological characteristics}

Among the 138 patients, 59 patients (42.8\%) were included in the sarcopenia group and 79 patients $(57.2 \%)$ were included in the nonsarcopenia group. A total of 12 gNET patients, 52 gNEC patients, and 74 gMANEC patients were included in this study. Of gNET patients, 6 patients were type 1,5 patients were type 2 , and 1 patient was type 3 . The comparison of clinical data between the two groups showed a higher incidence of sarcopenia in the subgroups of male patients, aged 65 years, with a BMI of $<25$ and a tumor larger than $50 \mathrm{~mm}$ (all 
Table 1 Clinicopathological characteristics

\begin{tabular}{|c|c|c|c|c|}
\hline Variable & All $(n=138)$ & Low $(n=59)$ & High $(n=79)$ & $\mathbf{P}$ \\
\hline Gender & & & & 0.014 \\
\hline Male & 105 & 51 & 54 & \\
\hline Female & 33 & 8 & 25 & \\
\hline Age(years) & & & & 0.004 \\
\hline$<65$ & 80 & 26 & 54 & \\
\hline$\geq 65$ & 58 & 33 & 25 & \\
\hline $\mathrm{BMI}(\mathrm{kg} / \mathrm{m} 2)$ & & & & 0.007 \\
\hline$<25$ & 115 & 55 & 60 & \\
\hline$\geq 25$ & 23 & 4 & 19 & \\
\hline ASA & & & & 0.664 \\
\hline 1 & 69 & 28 & 41 & \\
\hline 2 & 54 & 23 & 31 & \\
\hline 3 & 15 & 8 & 7 & \\
\hline Comorbidities & & & & 0.471 \\
\hline No & 40 & 19 & 21 & \\
\hline Yes & 98 & 40 & 58 & \\
\hline Tumor diameter(mm) & & & & 0.037 \\
\hline$<50$ & 68 & 23 & 45 & \\
\hline$\geq 50$ & 70 & 36 & 34 & \\
\hline Tumor location & & & & 0.783 \\
\hline Upper & 63 & 26 & 37 & \\
\hline Middle & 27 & 12 & 15 & \\
\hline Lower & 33 & 16 & 17 & \\
\hline Mix & 15 & 5 & 10 & \\
\hline T stage & & & & 0.471 \\
\hline $\mathrm{T} 1+\mathrm{T} 2$ & 77 & 35 & 42 & \\
\hline $\mathrm{T} 3+\mathrm{T} 4$ & 61 & 24 & 37 & \\
\hline N stage & & & & 0.181 \\
\hline NO & 46 & 16 & 30 & \\
\hline $\mathrm{N} 1$ & 92 & 43 & 49 & \\
\hline Surgical method & & & & 0.103 \\
\hline Open & 43 & 14 & 29 & \\
\hline Laparoscopic & 95 & 45 & 50 & \\
\hline Gastrectomy extent & & & & 0.67 \\
\hline Total & 101 & 45 & 56 & \\
\hline Distal & 33 & 13 & 20 & \\
\hline Proximal & 4 & 1 & 3 & \\
\hline Pathological type & & & & 0.318 \\
\hline NET & 12 & 3 & 9 & \\
\hline NEC & 52 & 21 & 31 & \\
\hline MANEC & 74 & 35 & 39 & \\
\hline Ki-67 positive index (\%) & & & & 0.439 \\
\hline$<60$ & 59 & 23 & 36 & \\
\hline$\geq 60$ & 79 & 36 & 43 & \\
\hline
\end{tabular}


Table 1 Clinicopathological characteristics (Continued)

\begin{tabular}{llll}
\hline Variable & All $(\boldsymbol{n = 1 3 8 )}$ & Low $(\boldsymbol{n}=\mathbf{5 9})$ & High $(\boldsymbol{n}=\mathbf{7 9})$ \\
\hline Complications & & & $\mathbf{P}$ \\
No & 82 & 35 & 47 \\
Yes & 56 & 24 & 32 \\
Adjuvant chemotherapy & & & \\
No & 66 & 32 & 34 \\
Yes & 72 & 27 & 45 \\
\hline
\end{tabular}

SMI Skeletal muscle index, BMI Body mass index, ASA American Society of Anesthesiologists, NET Neuroendocrine tumor, NEC Neuroendocrine carcinoma, MANEC Mixed adenoneuroendocrine carcinoma

$p<0.05)$. However, no significant differences in the other variables were observed between the two groups (all $p>0.05$ ) (Table 1).

\section{Effects of sarcopenia on postoperative complications} In the present study, postoperative complications occurred in 44 patients (31.9\%), and serious complications occurred in 3 patients (2.2\%). The incidence of total postoperative complications was 33.9 and $30.4 \%$, and the incidence of serious complications was 0 and $3.7 \%$ in the sarcopenia group and the nonsarcopenia group, respectively (all $p>0.05$ ). Postoperative surgical and systemic complications occurred in 20 patients $(14.5 \%)$ and 24 patients $(17.4 \%)$, respectively, in the whole group. In the sarcopenia group and the nonsarcopenia group, the incidence of postoperative surgical complications was 13.6 and $15.2 \%$, and the incidence of postoperative systemic complications was 20.3 and $15.2 \%$, respectively (all $p>0.05$ ). In addition, the analysis did not reveal significant differences in the incidence of specific types of complications defined according to the physical location of the complication between the two groups (all $p>0.05$ ) (Table 2).

Table 2 Postoperative complications in 138 patients [Case(\%)]

\begin{tabular}{llll}
\hline & Sarcopenia & Nonsarcopenia & P \\
\hline Total complications & $20(33.9)$ & $24(30.4)$ & 0.661 \\
Serious complications & $0(0)$ & $3(3.7)$ & 0.26 \\
Surgical complications & $8(13.6)$ & $12(15.2)$ & 0.788 \\
Systemic complications & $12(20.3)$ & $12(15.2)$ & 0.43 \\
Physical location & & & \\
Pulmonary infection & $12(20.3)$ & $12(15.2)$ & 0.43 \\
Abdominal infection & $4(6.8)$ & $3(3.8)$ & 0.461 \\
Incision infection & $1(1.7)$ & $0(0)$ & 0.428 \\
Chylous fistula & $0(0)$ & $3(3.8)$ & 0.26 \\
Intestinal obstruction & $0(0)$ & $2(2.5)$ & 0.507 \\
Anastomotic fistula & $1(1.7)$ & $2(2.5)$ & 1 \\
Abdominal bleeding & $1(1.7)$ & $2(2.5)$ & 1 \\
Anastomotic stenosis & $1(1.7)$ & $0(0)$ & 0.428 \\
\hline
\end{tabular}

Effects of sarcopenia on the prognosis of patients with gNENs

The 3-year OS rates were 42.37 and $65.82 \%$, and the 3 year RFS rates were 52.54 and $68.35 \%$ in the sarcopenia and nonsarcopenia groups, respectively (all $p<0.05$, Fig. $1 \mathrm{a}-\mathrm{b})$. According to the univariate analysis, the Anesthesiology Society of America (ASA) score, pathological $\mathrm{T}$ stage $(\mathrm{pT})$, pathological $\mathrm{N}$ stage $(\mathrm{pN})$, Ki-67positive index and sarcopenia were related to the 3-year OS rates, whereas the ASA score, pN, Ki-67-positive index, and sarcopenia were related to the 3-year RFS rates (all $p<0.05$, Table 3 ). The multivariate analysis only identified relations between the ASA score, pN, Ki67-positive index and sarcopenia with the 3 -year OS and RFS rates (all $\mathrm{p}<0.05$, Table 3 ).

\section{Effects of sarcopenia on the prognosis of patients with different types of $\mathrm{g}$-NENs}

According to the analysis stratified by postoperative pathological types, the 3-year OS rates of the sarcopenia group and nonsarcopenia group of patients with gNET were 66.67 and $77.78 \%$, respectively, and the 3-year RFS rates were 66.67 and $66.67 \%$, respectively (all $p>0.05$, Fig. $1 \mathrm{c}$-d). Among patients with gNEC, the 3-year OS rates of the sarcopenia group and nonsarcopenia group were 42.86 and $54.84 \%$, respectively, and the 3-year RFS rates were 52.38 and $61.29 \%$, respectively (all $p>0.05$, Fig. 1e-f). Among patients with gMANEC, the 3-year OS rates of the sarcopenia group and nonsarcopenia group were 40.00 and $71.79 \%$, respectively, and the 3-year RFS rates were 51.43 and $74.36 \%$, respectively (all $p<0.05$, Fig. 1g-h). To, We subsequently performed a multivariate analysis of each subgroup of the population to more accurately evaluate the effect of sarcopenia on the prognosis of patients with different types of g-NENs. However, because few patients were included in the gNET subgroup, the Kaplan-Meier analysis did not reveal a significant difference between the two groups in the gNET subgroup. Therefore, the gNET subgroup was not included in further multivariate analyses. The multivariate analysis revealed associations between the 3-year OS rates and comorbidities, $\mathrm{pN}$ and the $\mathrm{Ki}-67$-positive index 

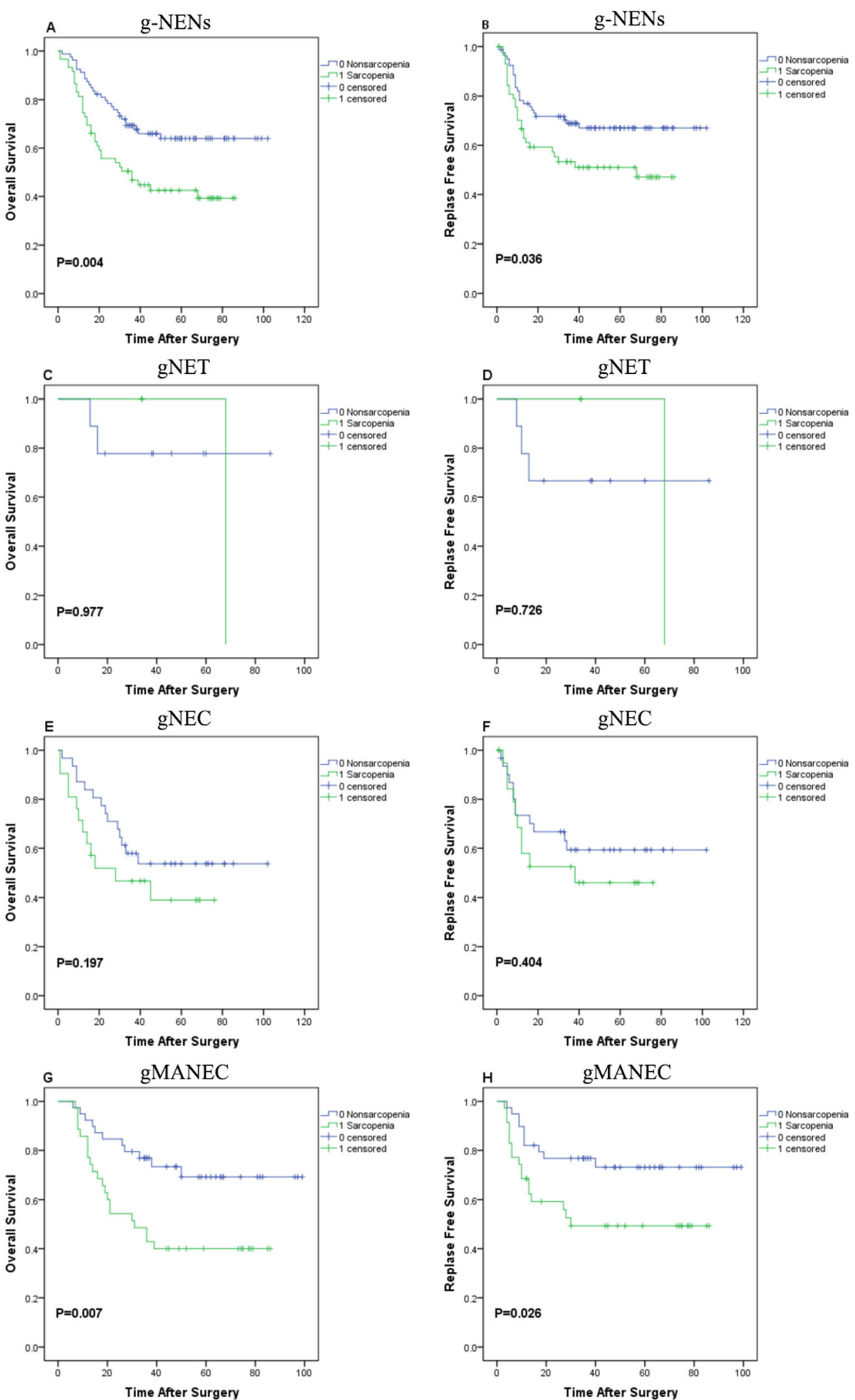

Fig. 1 Kaplan-Meier analysis of the 3-year overall survival (OS) and recurrence-free survival (RFS) rates of patients with gastric neuroendocrine neoplasms ( $g$-NENs) stratified according to the presence of sarcopenia (a-b) and pathological types: $\mathbf{c}-\mathbf{d}$ gastric neuroendocrine tumor (gNET), e-f gastric neuroendocrine carcinoma (gNEC), and (g-h) gastric mixed adenoneuroendocrine carcinoma (gMANEC) 
Table 3 Uni- and multivariate analyses of factors associated with 3-year overall survival (OS) and recurrence-free survival (RFS) rates in g-NENs patients

\begin{tabular}{|c|c|c|c|c|c|c|c|c|}
\hline \multirow[t]{3}{*}{ Variable } & \multicolumn{2}{|l|}{ Univariate analysis } & \multicolumn{2}{|c|}{ Multivariate analysis } & \multicolumn{2}{|l|}{ Univariate analysis } & \multicolumn{2}{|l|}{ Multivariate analysis } \\
\hline & \multicolumn{2}{|l|}{ 3-year OS } & \multicolumn{2}{|l|}{ 3-year OS } & \multicolumn{2}{|l|}{ 3-year RFS } & \multicolumn{2}{|l|}{ 3-year RFS } \\
\hline & HR $(95 \% \mathrm{Cl})$ & $P$ & HR $(95 \% \mathrm{Cl})$ & $P$ & HR $(95 \% \mathrm{Cl})$ & $P$ & HR (95\% Cl) & $P$ \\
\hline \multicolumn{9}{|l|}{ Gender } \\
\hline Male & 1 & & & & 1 & & & \\
\hline Female & $0.650(0.338-1.248)$ & 0.195 & & & $0.813(0.419-1.580)$ & 0.542 & & \\
\hline \multicolumn{9}{|l|}{ Age (years) } \\
\hline$<65$ & 1 & & & & 1 & & & \\
\hline$\geq 65$ & $1.112(0.669-1.847)$ & 0.683 & & & $0.851(0.488-1.483)$ & 0.569 & & \\
\hline \multicolumn{9}{|l|}{$\mathrm{BMI}(\mathrm{kg} / \mathrm{m} 2)$} \\
\hline$<25$ & 1 & & & & 1 & & & \\
\hline$\geq 25$ & $0.694(0.330-1.460)$ & 0.336 & & & $0.709(0.320-1.570)$ & 0.396 & & \\
\hline \multicolumn{9}{|l|}{ ASA } \\
\hline 1 & 1 & & 1 & & 1 & & 1 & \\
\hline 2 & $1.934(1.118-3.347)$ & 0.018 & 1.869 (1.069-3.269) & 0.028 & $2.118(1.196-3.749)$ & 0.010 & $2.191(1.223-3.924)$ & 0.008 \\
\hline 3 & $2.54(1.172-5.504)$ & 0.018 & $2.029(0.917-4.486)$ & 0.081 & $1.294(0.487-3.437)$ & 0.605 & $0.875(0.324-2.361)$ & 0.791 \\
\hline \multicolumn{9}{|l|}{ Comorbidity } \\
\hline No & 1 & & & & 1 & & & \\
\hline Yes & $1.346(0.751-2.411)$ & 0.318 & & & $0.993(0.552-1.785)$ & 0.981 & & \\
\hline \multicolumn{9}{|l|}{ Tumor (mm) } \\
\hline$<50$ & 1 & & & & 1 & & & \\
\hline$\geq 50$ & $1.596(0.957-2.659)$ & 0.073 & & & $1.449(0.841-2.496)$ & 0.181 & & \\
\hline \multicolumn{9}{|l|}{ Tumor location } \\
\hline Upper & 1 & & & & 1 & & & \\
\hline Middle & $0.664(0.314-1.403)$ & 0.283 & & & $0.778(0.349-1.734)$ & 0.540 & & \\
\hline Lower & $0.917(0.484-1.735)$ & 0.789 & & & $1.104(0.571-2.135)$ & 0.769 & & \\
\hline Mix & $1.253(0.593-2.649)$ & 0.555 & & & $1.147(0.494-2.664)$ & 0.749 & & \\
\hline \multicolumn{9}{|l|}{ T stage } \\
\hline $\mathrm{T} 1+\mathrm{T} 2$ & 1 & & 1 & & 1 & & & \\
\hline $\mathrm{T} 3+\mathrm{T} 4$ & $1.748(1.054-2.898)$ & 0.031 & $1.445(0.843-2.476)$ & 0.181 & $1.568(0.914-2.691)$ & 0.103 & & \\
\hline \multicolumn{9}{|l|}{ N stage } \\
\hline No & 1 & & 1 & & 1 & & 1 & \\
\hline N1 & $5.032(2.385-10.616)$ & $<.001$ & 3.554 (1.624-7.778) & 0.002 & $5.882(2.507-13.804)$ & $<.001$ & $4.710(1.966-11.283)$ & 0.001 \\
\hline \multicolumn{9}{|l|}{ Surgical method } \\
\hline Open & 1 & & & & 1 & & & \\
\hline Laparoscopic & $0.797(0.472-1.344)$ & 0.395 & & & $0.875(0.496-1.546)$ & 0.647 & & \\
\hline \multicolumn{9}{|c|}{ Gastrectomy extent } \\
\hline Total & 1 & & & & 1 & & & \\
\hline Distal & $0.74(0.400-1.368)$ & 0.337 & & & $1.080(0.584-1.994)$ & 0.807 & & \\
\hline Proximal & $0.418(0.058-3.029)$ & 0.388 & & & $0.528(0.072-3.850)$ & 0.529 & & \\
\hline \multicolumn{9}{|l|}{ Pathological type } \\
\hline NET & 1 & & & & 1 & & & \\
\hline NEC & $2.352(0.712-7.773)$ & 0.161 & & & $1.521(0.524-4.414)$ & 0.441 & & \\
\hline MANEC & $1.839(0.563-6.008)$ & 0.313 & & & $1.172(0.410-3.350)$ & 0.767 & & \\
\hline
\end{tabular}


Table 3 Uni- and multivariate analyses of factors associated with 3-year overall survival (OS) and recurrence-free survival (RFS) rates in g-NENs patients (Continued)

\begin{tabular}{|c|c|c|c|c|c|c|c|c|}
\hline \multirow[t]{3}{*}{ Variable } & \multicolumn{2}{|l|}{ Univariate analysis } & \multirow{2}{*}{\multicolumn{2}{|c|}{$\begin{array}{l}\text { Multivariate analysis } \\
\text { 3-year OS }\end{array}$}} & \multirow{2}{*}{\multicolumn{2}{|c|}{$\begin{array}{l}\text { Univariate analysis } \\
\text { 3-year RFS }\end{array}$}} & \multirow{2}{*}{\multicolumn{2}{|c|}{$\begin{array}{l}\text { Multivariate analysis } \\
\text { 3-year RFS }\end{array}$}} \\
\hline & \multicolumn{2}{|l|}{ 3-year OS } & & & & & & \\
\hline & HR $(95 \% \mathrm{Cl})$ & $P$ & $\mathrm{HR}(95 \% \mathrm{Cl})$ & $P$ & HR $(95 \% \mathrm{Cl})$ & $P$ & $\mathrm{HR}(95 \% \mathrm{Cl})$ & $\mathbf{P}$ \\
\hline \multicolumn{9}{|c|}{ Ki-67 positive index (\%) } \\
\hline$<60$ & 1 & & 1 & & 1 & & 1 & \\
\hline$\geq 60$ & $4.753(2.469-9.152)$ & $<.001$ & $3.492(1.772-6.879)$ & $<.001$ & $5.978(2.810-12.718)$ & $<.001$ & $4.304(1.981-9.350)$ & $<.001$ \\
\hline \multicolumn{9}{|c|}{ Complication } \\
\hline No & 1 & & & & 1 & & & \\
\hline Yes & $1.645(0.994-2.723)$ & 0.053 & & & $1.245(0.699-2.220)$ & 0.457 & & \\
\hline \multicolumn{9}{|c|}{ Adjuvant chemotherapy } \\
\hline No & 1 & & & & 1 & & & \\
\hline Yes & $1.409(0.843-2.355)$ & 0.191 & & & 1.559 (0.894-2.719) & 0.117 & & \\
\hline \multicolumn{9}{|c|}{ Martin et al. [27] } \\
\hline High & 1 & & & & 1 & & & \\
\hline Low & 1.181 (0.709-1.968) & 0.523 & & & $1.377(0.790-2.400)$ & 0.260 & & \\
\hline \multicolumn{9}{|l|}{ SMI } \\
\hline High & 1 & & 1 & & 1 & & 1 & \\
\hline Low & $2.061(1.243-3.420)$ & 0.005 & $2.098(1.239-3.553)$ & 0.006 & $1.758(1.025-3.018)$ & 0.041 & $1.780(1.029-3.076)$ & 0.039 \\
\hline
\end{tabular}

g-NENs gastric neuroendocrine neoplasms, HR Hazard ratio, Cl Confidence interval, BMI Body mass index, ASA American Society of Anesthesiologists, NET

Neuroendocrine tumor, NEC Neuroendocrine carcinoma, MANEC Mixed adenoneuroendocrine carcinoma, SMI Skeletal muscle index

(all $p<0.05$ ), and the 3-year RFS rates were associated with $\mathrm{pN}$ and the Ki-67-positive index (all $\mathrm{p}<0.05$ ); neither OS rates nor RFS rates were associated with sarcopenia in patients with gNEC (Supplemental Table 2). However, in patients gMANEC, the pN, Ki-67-positive index and sarcopenia were related to the 3-year OS rates and the 3 -year RFS rates (all p $<0.05$, Table 4).

\section{Discussion}

g-NENs are a type of digestive system tumor with different clinical symptoms and biological characteristics [28]. Patients with different prognoses must be identified according to their clinical and pathological conditions to provide individualized treatment and improve the efficacy of g-NEN treatments. However, few studies have evaluated the prognostic factors for patients with gNENs [8, 9]. Recently, the effects of preoperative body composition parameters (such as skeletal muscle mass) on postoperative short-term and long-term outcomes has attracted the attention of scholars in the East and the West. Sarcopenia is characterized by a progressive decrease in systemic muscle mass, muscle strength, or muscle physiological function associated with aging [29]. Sarcopenia has been shown to be closely related to the prognosis of patients with various malignant tumors [10-16]. However, the effect of sarcopenia on the prognosis of patients with g-NENs undergoing radical gastrectomy has not been reported. Therefore, this study combined the clinicopathological data from 138 patients treated at two institutions to explore the effects of sarcopenia on the short-term and long-term postoperative outcomes of patients with g-NENs.

Based on the definition of sarcopenia provided by the European Working Group on Sarcopenia (EWGSOP) [30] and the Asian Working Group for Sarcopenia (AWGS) [31], sarcopenia is characterized by a low skeletal muscle mass, low muscle strength and poor low physical performance. However, in the current study, low skeletal muscle mass was used as the main definition of sarcopenia. A meta-analysis exploring the relationship between sarcopenia and the risk of postoperative complications of gastrointestinal tumors included 29 studies related to sarcopenia, of which 26 used low skeletal muscle mass as the definition of sarcopenia [32]. In both studies from Eastern [10, 11] and Western [21, 27, 29] countries, researchers tend to use a low skeletal muscle mass as the definition for sarcopenia. Data on the patient's muscle mass are obtained by analyzing the abdominal CT scan [10]. An abdominal CT scan is also a routine follow-up test performed in patients with gNENs after radical gastrectomy [33]. The use of a low skeletal muscle mass as the definition for sarcopenia may help clinicians to make treatment decisions more conveniently and quickly.

Currently, the value of the cutoff point of sarcopenia remains controversial. The most commonly used definitions were provided by Prado et al. [21] and Martin et al. [27]. In the past, our center used X-tile software to 
Table 4 Uni- and multivariate analyses of factors associated with 3-year overall survival (OS) and recurrence-free survival (RFS) rates in gMANEC patients

\begin{tabular}{|c|c|c|c|c|c|c|c|c|}
\hline \multirow[t]{3}{*}{ Variable } & \multicolumn{2}{|l|}{ Univariate analysis } & \multirow{2}{*}{\multicolumn{2}{|c|}{$\frac{\text { Multivariate analysis }}{3 \text {-year OS }}$}} & \multirow{2}{*}{\multicolumn{2}{|c|}{$\begin{array}{l}\text { Univariate analysis } \\
\text { 3-year RFS }\end{array}$}} & \multirow{2}{*}{\multicolumn{2}{|c|}{$\begin{array}{l}\text { Multivariate analysis } \\
\text { 3-year RFS }\end{array}$}} \\
\hline & \multicolumn{2}{|l|}{ 3-year OS } & & & & & & \\
\hline & HR (95\% Cl) & $P$ & HR (95\% Cl) & $\mathbf{P}$ & HR (95\% Cl) & $P$ & HR (95\% Cl) & $P$ \\
\hline \multicolumn{9}{|l|}{ Gender } \\
\hline Male & 1 & & & & 1 & & & \\
\hline Female & $0.788(0.341-1.823)$ & 0.578 & & & $1.020(0.431-2.412)$ & 0.964 & & \\
\hline \multicolumn{9}{|l|}{ Age (years) } \\
\hline$<65$ & 1 & & & & 1 & & & \\
\hline$\geq 65$ & $1.234(0.616-2.472)$ & 0.554 & & & $0.929(0.431-2.002)$ & 0.851 & & \\
\hline \multicolumn{9}{|l|}{ BMI(kg/m2) } \\
\hline$<25$ & 1 & & & & 1 & & & \\
\hline$\geq 25$ & $0.856(0.300-2.442)$ & 0.772 & & & $0.809(0.243-2.687)$ & 0.729 & & \\
\hline \multicolumn{9}{|l|}{ ASA } \\
\hline 1 & 1 & & 1 & & 1 & & 1 & \\
\hline 2 & $2.261(1.038-4.929)$ & 0.04 & $1.548(0.701-3.422)$ & 0.280 & $2.573(1.141-5.801)$ & 0.041 & $2.089(0.917-4.758)$ & 0.080 \\
\hline 3 & $3.732(1.371-10.156)$ & 0.01 & $1.898(0.628-5.730)$ & 0.256 & $1.563(0.429-5.695)$ & 0.499 & $0.744(0.197-2.813)$ & 0.663 \\
\hline \multicolumn{9}{|l|}{ Comorbidity } \\
\hline No & 1 & & & & 1 & & & \\
\hline Yes & $0.846(0.401-1.789)$ & 0.662 & & & $0.528(0.245-1.139)$ & 0.104 & & \\
\hline \multicolumn{9}{|l|}{ Tumor (mm) } \\
\hline$<50$ & 1 & & & & 1 & & & \\
\hline$\geq 50$ & $1.528(0.754-3.098)$ & 0.239 & & & $1.264(0.591-2.701)$ & 0.546 & & \\
\hline \multicolumn{9}{|l|}{ Tumor location } \\
\hline Upper & 1 & & & & 1 & & & \\
\hline Middle & $0.573(0.188-1.741)$ & 0.326 & & & $0.802(0.255-2.521)$ & 0.706 & & \\
\hline Lower & $0.852(0.369-1.970)$ & 0.708 & & & $1.100(0.456-2.656)$ & 0.832 & & \\
\hline Mix & $1.625(0.583-4.531)$ & 0.353 & & & $1.140(0.317-4.094)$ & 0.841 & & \\
\hline \multicolumn{9}{|l|}{ T stage } \\
\hline $\mathrm{T} 1+\mathrm{T} 2$ & 1 & & 1 & & 1 & & & \\
\hline $\mathrm{T} 3+\mathrm{T} 4$ & $2.197(1.082-4.464)$ & 0.029 & $2.145(0.985-4.668)$ & 0.055 & $1.753(0.818-3.756)$ & 0.149 & & \\
\hline \multicolumn{9}{|l|}{ N stage } \\
\hline NO & 1 & & 1 & & 1 & & 1 & \\
\hline $\mathrm{N} 1$ & $4.586(1.756-11.979)$ & 0.002 & $3.134(1.148-8.551)$ & 0.026 & 4.558 (1.568-13.249) & 0.005 & $3.956(1.313-11.917)$ & 0.015 \\
\hline \multicolumn{9}{|l|}{ Surgical method } \\
\hline Open & 1 & & & & 1 & & & \\
\hline Laparoscopic & $0.698(0.330-1.474)$ & 0.346 & & & $0.778(0.340-1.779)$ & 0.552 & & \\
\hline \multicolumn{9}{|c|}{ Gastrectomy extent } \\
\hline Total & 1 & & & & 1 & & & \\
\hline Distal & $0.691(0.310-1.540)$ & 0.366 & & & $1.201(0.539-2.673)$ & 0.654 & & \\
\hline Proximal & $0(0)$ & 0.982 & & & $0(0)$ & 0.984 & & \\
\hline \multicolumn{9}{|c|}{ Ki-67 positive index (\%) } \\
\hline$<60$ & 1 & & 1 & & 1 & & 1 & \\
\hline$\geq 60$ & 4.874 (1.872-12.689) & 0.001 & $3.710(1.372-10.033)$ & 0.010 & $11.553(2.729-48.913)$ & 0.001 & $8.210(1.912-35.256)$ & 0.005 \\
\hline
\end{tabular}

Complication 
Table 4 Uni- and multivariate analyses of factors associated with 3-year overall survival (OS) and recurrence-free survival (RFS) rates in gMANEC patients (Continued)

\begin{tabular}{|c|c|c|c|c|c|c|c|c|}
\hline \multirow[t]{3}{*}{ Variable } & \multirow{2}{*}{\multicolumn{2}{|c|}{$\begin{array}{l}\text { Univariate analysis } \\
\text { 3-year OS }\end{array}$}} & \multirow{2}{*}{\multicolumn{2}{|c|}{$\begin{array}{l}\text { Multivariate analysis } \\
\text { 3-year OS }\end{array}$}} & \multirow{2}{*}{\multicolumn{2}{|c|}{$\begin{array}{l}\text { Univariate analysis } \\
\text { 3-year RFS }\end{array}$}} & \multirow{2}{*}{\multicolumn{2}{|c|}{$\frac{\text { Multivariate analysis }}{\text { 3-year RFS }}$}} \\
\hline & & & & & & & & \\
\hline & HR $(95 \% \mathrm{Cl})$ & $P$ & HR $(95 \% \mathrm{Cl})$ & $P$ & $\mathrm{HR}(95 \% \mathrm{Cl})$ & $P$ & HR (95\% Cl) & $P$ \\
\hline No & 1 & & & & 1 & & & \\
\hline Yes & $1.645(0.820-3.298)$ & 0.161 & & & $1.200(0.525-2.742)$ & 0.666 & & \\
\hline \multicolumn{9}{|c|}{ Adjuvant chemotherapy } \\
\hline No & 1 & & & & 1 & & & \\
\hline Yes & $1.428(0.697-2.925)$ & 0.33 & & & $1.248(0.579-2.691)$ & 0.572 & & \\
\hline \multicolumn{9}{|c|}{ Martin et al. [27] } \\
\hline High & 1 & & & & 1 & & & \\
\hline Low & 1.667 (0.789-3.523) & 0.181 & & & $1.868(0.817-4.272)$ & 0.138 & & \\
\hline \multicolumn{9}{|l|}{ SMl } \\
\hline High & 1 & & 1 & & 1 & & 1 & \\
\hline Low & 2.639 (1.270-5.483) & 0.009 & $2.735(1.246-6.001)$ & 0.012 & $2.356(1.077-5.153)$ & 0.032 & $2.825(1.250-6.386)$ & 0.013 \\
\hline
\end{tabular}

gMANEC gastric mixed adenoneuroendocrine carcinoma, HR Hazard ratio, Cl Confidence interval, BMI Body mass index, ASA American Society of Anesthesiologists, $S M I$ Skeletal muscle index

analyze the 3-year OS rates of 924 patients with gastric adenocarcinoma after $\mathrm{R} 0$ resection and defined sarcopenia as a $\mathrm{SMI}<32.5 \mathrm{~cm}^{2} / \mathrm{m}^{2}$ for males and a $\mathrm{SMI}<28.6$ $\mathrm{cm}^{2} / \mathrm{m}^{2}$ for females [10]. However, when previous definitions were applied, only the definitions reported by Martin et al. obtained a prevalence of sarcopenia similar to the values reported in previous studies (Supplementary Table 3). Therefore, we included the cutoff point defined by Martin et al. in the analysis. The KaplanMeier analysis and Cox regression analysis indicated that the cutoff points defined by Martin et al. were unable to serve as prognostic factors for patients with g-NENs in our study (Tables 3 and 4, Supplemental Table 2, and Supplementary Fig. 3). Therefore, this study used X-tile software to analyze the 3-year OS rates of 138 patients with g-NENs from the two institutions and defined a $\mathrm{SMI}<44.3 \mathrm{~cm}^{2} / \mathrm{m}^{2}$ for males and a $\mathrm{SMI}<32.4 \mathrm{~cm}^{2} / \mathrm{m}^{2}$ for females as sarcopenia, and the incidence of sarcopenia in our study was $42.8 \%(59 / 138)$. A significance difference in survival was not observed among the female group (Supplementary Fig. 2), perhaps because the proportion of female patients in this study was relatively small (33/138 cases, 23.9\%). However, in the previous studies of sarcopenia, different values for the cutoff point of sarcopenia are usually used in male and female groups $[14,15,27,34]$, mainly because substantial differences in the strength and quality of skeletal muscle exist between males and females. In the present study, we compared the average SMI in male and female patients with gNENs and observed a significant difference in the average value of the SMI between males and females (45.2 $\mathrm{cm}^{2} / \mathrm{m}^{2}$ in male, $37.5 \mathrm{~cm}^{2} / \mathrm{m}^{2}$ in female, $\left.p<0.05\right)$. Therefore, we used different diagnostic criteria for men and women in this study to better evaluate the effect of sarcopenia on the prognosis of patients with g-NENs.

The effect of sarcopenia on short-term postoperative outcomes in patients with malignant tumors remains controversial. Previous studies have confirmed that sarcopenia is associated with the postoperative short-term prognosis in patients with multiple malignant tumors $[11,13,15,35]$. In a Chinese study, an analysis of 937 patients with gastric cancer after radical gastrectomy showed that sarcopenia was related to severe postoperative complications [11]. An American study identified an association between sarcopenia and the short-term outcomes in patients with pancreatic cancer after pancreatectomy [35]. However, some studies have reported the opposite results $[34,36]$. As shown in the study by Tegels [34], the incidence of sarcopenia is higher in patients with gastric cancer, but it is not associated with a poor postoperative prognosis. According to Ouchi [36], sarcopenia does not increase the incidence of total and severe postoperative complications in patients with colorectal cancer [36]. In the present study, significant differences in the incidences of total postoperative complications, surgical complications and systemic complications were not observed between the patients with g-NENs presenting with and without sarcopenia. After stratification according to the physical location of the complications, significant correlations were not observed between sarcopenia and specific types of complications in patients with g-NENs.

In recent years, studies have confirmed that sarcopenia is closely related to the long-term prognoses of patients with multiple malignant tumors $[10,12,14,16]$. Studies by Voron have identified sarcopenia as an independent 
prognostic factor for long-term outcomes in patients with hepatocellular carcinoma after hepatectomy [12]. As shown in the study by Tan, sarcopenia is associated with a poor prognosis for patients with pancreatic cancer [16]. Similar to previous studies, preoperative sarcopenia was an independent risk factor for the longterm prognosis of patients with g-NENs in the present study. We also examined the interactions between sarcopenia and the gastrectomy status and tumor aggressiveness. No significant differences in surgical methods, the extent of laparoscopic gastrectomy and pathological stages were observed between the sarcopenia group and the nonsarcopenia group (Table 1). The multivariate analysis identified the $\mathrm{pN}$ stage and sarcopenia as independent prognostic factors for 3-year OS and RFS rates in patients with g-NENs, while surgical methods, the extent of laparoscopic gastrectomy and $\mathrm{pT}$ stage were not associated with survival (Table 3). The HR value of sarcopenia changed little between the univariate and multivariate analyses in our study (Table 3 ). Thus, the prognostic effect of preoperative sarcopenia is less affected by the gastrectomy status and tumor aggressiveness in patients with g-NENs. However, g-NENs are divided into three different pathological types, namely, gNET, gNEC, and gMANEC. The degree of tumor differentiation, grade, and cellular components of the three pathological types are not the same [4], and the treatment strategy and prognosis are also significantly different in patients with different pathological types [37]. In the present study, a further stratified analysis showed relations between sarcopenia and the 3-year OS and RFS rates in patients with gMANEC. Potential explanations for this result are provided below. First, for the subgroup of the gNET population, gNET is a highly differentiated neuroendocrine tumor, with mainly low or moderate malignancy, and presents as stage G1 and G2 [3]. The lower tumor invasiveness and the lower effect on skeletal muscle mass may explain why sarcopenia is not useful as a prognostic factor for patients with gNET. This result also may caused by the relatively small number of gNET patients, further study may be required. Second, compared with gNEC and gMANEC, gNEC is a poorly differentiated neuroendocrine carcinoma, which is generally highly malignant and manifests as stage G3. gMANEC is defined as a malignant tumor with morphological components of glandular epithelial cells and neuroendocrine cells, both of which account for at least more than $30 \%$ of the total cells [4]. The clinical characteristics of gMANEC generally depend on the proportion of neuroendocrine carcinoma components [38, 39]. Fernandes et al. postulated that the prognosis of patients with gMANEC might be related to whether certain tumor components are more invasive [40]. Furthermore, previous studies have confirmed that sarcopenia is associated with the long-term prognosis of patients with gastric adenocarcinoma [10, 11]. Therefore, we propose that the mechanism may be modulated by the presence of more adenocarcinoma components in gMANEC, and thus, sarcopenia is only related to the long-term prognosis of patients with gMANEC, but not the patients with gNET and gNEC, in the present study. The underlying molecular mechanism must be further elucidated. This result may be caused by the sample sizes of individual subgroups. Further study with bigger sample sizes of different pathological types needed to be conducted.

This study had some limitations. First, because most patients with gNET received endoscopic treatment, the number of patients with gNET included in this study was limited, which may cause bias. Second, this study employed a retrospective case-control design and was conducted in an Asian population; therefore, the results must be confirmed by prospective studies and data from Western countries. Third, the proportion of female patients in this study is relatively small (33/138 cases, $23.9 \%$ ), and thus the prognostic effect of sarcopenia on female patients with g-NENs must be further analyzed in a study with a larger population. We plan to conduct related studies in the future. Fourth, this study did not analyze the effects of postoperative adjuvant chemotherapy and postoperative sarcopenia caused by the gastrectomy status and tumor aggressiveness on long-term outcomes, which may also bias the results. Fifth, Due to the relatively few cases of stratified analysis of pathological subtypes, we did not identify sarcopenia scores related to tumour type gNET, gNEC and gMANEC, and the prognostic value of sarcopenia for g-NENs may be biased. In the future, a larger sample size is needed to determine the best cut-off point of sarcopenia with different pathological types, and to verify the prognostic effect of sarcopenia on different pathological types of gNENs. Nevertheless, to our knowledge, this study is the first to explore the effects of sarcopenia on the shortterm and long-term outcomes in patients with g-NENs by using data from two independent large-volume institutions, thus providing a reference for future clinical trials.

\section{Conclusions}

In the present study, a $\mathrm{SMI}<44.3 \mathrm{~cm}^{2} / \mathrm{m}^{2}$ for males and a $\mathrm{SMI}<32.4 \mathrm{~cm}^{2} / \mathrm{m}^{2}$ for females were identified as the optimal cutoff points for sarcopenia in patients with gNENs. Sarcopenia was not significantly associated with postoperative complications in patients with g-NENs. Sarcopenia is an independent risk factor for the longterm prognosis of patients with gMANEC undergoing radical gastrectomy. Further multicenter prospective studies are needed to confirm the prognostic value of sarcopenia in patients with g-NENs. 


\section{Supplementary information}

Supplementary information accompanies this paper at https://doi.org/10. 1186/s12885-020-07506-9.

Additional file 1 : Supplemental Table 1. Clinicopathological characteristics of patients treated at FMUUH and FMUFAH.

Additional file 2 : Supplemental Table 2. Univariate and multivariate analyses of factors associated with 3-year overall survival (OS) and recurrence-free survival (RFS) rates in patients with gNEC.

Additional file $\mathbf{3}$ : Supplemental Table 3. Four cutoff points tested as thresholds to define sarcopenia and the prevalence of sarcopenia.

Additional file 4 : Supplemental Figure 1. Computed tomography (CT) image captured at the third lumbar vertebral (L3) level. The following skeletal muscles are outlined in red: rectus abdominis; psoas, quadratus lumborum, paraspinal, transverse abdominal, external oblique, internal oblique, and rectus abdominis muscles. This male patient with sarcopenia had an L3 muscle index of $52.35 \mathrm{~cm}^{2} / \mathrm{m}^{2}$.

Additional file 5 : Supplemental Figure 2. The cutoff points of the skeletal muscle index (SMI) for sarcopenia defined by $X$-tile software. (A) X-tile plots for males $\left(44.3 \mathrm{~cm}^{2} / \mathrm{m}^{2}, X^{2}=4.2611, p=0.038\right)$ and (B) females $\left(32.4 \mathrm{~cm}^{2} / \mathrm{m}^{2}, X^{2}=1.0039, p=0.214\right)$ are shown.

Additional file 6 : Supplemental Figure 3. Kaplan-Meier analysis of the 3-year overall survival (OS) and recurrence-free survival (RFS) rates of patients with gastric neuroendocrine neoplasms (g-NENs) stratified according to the presence of sarcopenia diagnosed by the skeletal muscle index (SMI) cutoff points (for male, $43.0 \mathrm{~cm} 2 / \mathrm{m} 2$ for $\mathrm{BMI}<25 \mathrm{~kg} / \mathrm{m} 2,53.0$ $\mathrm{cm} 2 / \mathrm{m} 2$ for $\mathrm{BMI} \geq 25 \mathrm{~kg} / \mathrm{m} 2$; for female, $41 \mathrm{~cm} 2 / \mathrm{m} 2$ ) defined by Martin et al. (A-B) and pathological types: (C-D) gastric neuroendocrine tumor (gNET), (E-F) gastric neuroendocrine carcinoma (gNEC), (G-H) gastric mixed adenoneuroendocrine carcinoma (gMANEC).

\section{Abbreviations}

g-NENs: gastric neuroendocrine neoplasms; OS: Overall survival; RFS: Recurrence-free survival; SMI: Skeletal muscle index; BMI: Body mass index; ASA: American Society of Anesthesiologists; gNET: gastric neuroendocrine tumor; gNEC: gastric neuroendocrine carcinoma; gMANEC: gastric mixed adenoneuroendocrine carcinoma

\section{Acknowledgements}

We thank Bin-bin Xu, Zhen Xue, Jun Lu for their assistance provided in patient screening and data input.

\section{Authors' contributions}

JBW, ZX, JL and QLH, CMH and CHZ conceived the study, analyzed the data, and drafted the manuscript; $\mathrm{CMH}, \mathrm{CHZ}$ helped critically revise the manuscript for important intellectual content; ZFZ, BBX, PL, JWX, YX, JXL, QYC, LLC, ML, RHT, ZNH and JLL helped collect data and design the study. All authors have read and approved the manuscript.

\section{Funding}

Supported by Construction Project of Fujian Province Minimally Invasive Medical Center (No. [2017]171). The second batch of special support funds for Fujian Province innovation and entrepreneurship talents (2016B013). Fujian science and technology innovation joint fund project (2017Y9004). Fujian science and technology innovation joint fund project (2017Y9011). Fujian science and technology innovation joint fund project (2018Y9041). Natural Science Foundation of Fujian Province (2019 J01155). Fujian provincial science and technology innovation joint fund project plan (2018Y9005).These funding bodies were independent of the study design, data collection, interpretation and manuscript writing.

\section{Availability of data and materials}

The datasets used and/or analyzed during the current study are available from the corresponding author on reasonable request.

\section{Ethics approval and consent to participate}

The study protocol conformed to the Ethics Committee of Fujian Medical University Union Hospital. Written consent was provided by the patients for their information to be stored in the hospital database and used in research. Patient records were anonymized and de-identified before analysis.

\section{Consent for publication}

Not applicable.

\section{Competing interests}

There are no conflicts of interest or financial ties to disclose from any of author.

\section{Author details}

${ }^{1}$ Department of Gastric Surgery, Fujian Medical University Union Hospital, No.29 Xinquan Road, Fuzhou 350001, Fujian Province, China. ${ }^{2}$ Department of General Surgery, Fujian Medical University Union Hospital, Fuzhou, China. ${ }^{3}$ Key Laboratory of Ministry of Education of Gastrointestinal Cancer, Fujian Medical University, Fuzhou, Fujian Province, China. ${ }^{4}$ Department of gastrointestinal surgery, the first Affiliated Hospital of Fujian Medical University, Fuzhou, Fujian Province, China. ${ }^{5}$ Department of Pathology, the School of Basic Medical Sciences, Fujian Medical University, Fuzhou, China.

Received: 29 May 2020 Accepted: 7 October 2020

Published online: 15 October 2020

References

1. Modlin IM, Lye KD, Kidd M. Carcinoid tumors of the stomach. Surg Oncol. 2003;12(2):153-72 PubMed PMID: 12946486

2. Yao JC, Hassan M, Phan A, Dagohoy C, Leary C, Mares JE, et al. One hundred years after "carcinoid": epidemiology of and prognostic factors for neuroendocrine tumors in 35,825 cases in the United States. J Clin Oncol. 2008;26(18):3063-72. https://doi.org/10.1200/jco.2007.15.4377 PubMed PMID: 18565894.

3. Dasari A, Shen C, Halperin D, Zhao B, Zhou S, Xu Y, et al. Trends in the incidence, prevalence, and survival outcomes in patients with neuroendocrine tumors in the United States. JAMA Oncol. 2017;3(10):133542. https://doi.org/10.1001/jamaoncol.2017.0589 PubMed PMID: 28448665.

4. Bosman FTCF, Hruban RH, Theise ND, editors. WHO classification of tumors of the digestive system. Lyon: IARC Press; 2010. p. 13-4.

5. Shah MH, Goldner WS, Halfdanarson TR, Bergsland E, Berlin JD, Halperin D, et al. NCCN guidelines insights: neuroendocrine and adrenal tumors, version 2.2018. J Natl Compr Cancer Netw. 2018;16(6):693-702. https://doi.org/10. 6004/jnccn.2018.0056 PubMed PMID: 29891520.

6. Tsikitis VL, Wertheim BC, Guerrero MA. Trends of incidence and survival of gastrointestinal neuroendocrine tumors in the United States: a seer analysis. J Cancer. 2012;3:292-302. https://doi.org/10.7150/jca.4502 PubMed PMID: 22773933.

7. Klöppel G, Perren A, Heitz PU. The gastroenteropancreatic neuroendocrine cell system and its tumors: the WHO classification. Ann N Y Acad Sci. 2004; 1014:13-27 PubMed PMID: 15153416.

8. Faggiano A, Ferolla P, Grimaldi F, Campana D, Manzoni M, Davì MV, et al. Natural history of gastro-entero-pancreatic and thoracic neuroendocrine tumors. Data from a large prospective and retrospective Italian epidemiological study: the NET management study. J Endocrinol Investig. 2012;35(9):817-23. https://doi.org/10.3275/8102 PubMed PMID: 22080849.

9. Lewkowicz E, Trofimiuk-Müldner M, Wysocka K, Pach D, Kiełtyka A, Stefańska A, et al. Gastroenteropancreatic neuroendocrine neoplasms: a 10-year experience of a single center. Pol Arch Med Wewn. 2015;125(5):337-46 PubMed PMID: 25924181.

10. Zheng ZF, Lu J, Zheng CH, Li P, Xie JW, Wang JB, et al. A novel prognostic scoring system based on preoperative sarcopenia predicts the long-term outcome for patients after R0 resection for Gastric Cancer: experiences of a high-volume center. Ann Surg Oncol. 2017;24(7):1795-803. https://doi.org/ 10.1245/s10434-017-5813-7 PubMed PMID: 28213789.

11. Zhuang CL, Huang DD, Pang WY, Zhou CJ, Wang SL, Lou N, et al. Sarcopenia is an independent predictor of severe postoperative complications and long-term survival after radical Gastrectomy for Gastric Cancer: analysis from a large-scale cohort. Medicine. 2016;95(13):e3164. https://doi.org/10.1097/md.0000000000003164 PubMed PMID: 27043677.

12. Voron T, Tselikas L, Pietrasz D, Pigneur F, Laurent A, Compagnon P, et al. Sarcopenia impacts on short- and long-term results of hepatectomy for hepatocellular carcinoma. Ann Surg. 2015;261(6):1173-83. https://doi.org/10. 1097/sla.0000000000000743 PubMed PMID: 24950264. 
13. Malietzis G, Currie AC, Athanasiou T, Johns N, Anyamene N, Glynne-Jones R, et al. Influence of body composition profile on outcomes following colorectal cancer surgery. Br J Surg. 2016;103(5):572-80. https://doi.org/10. 1002/bjs.10075 PubMed PMID: 26994716.

14. Miyamoto Y, Baba Y, Sakamoto Y, Ohuchi M, Tokunaga R, Kurashige J, et al. Sarcopenia is a negative prognostic factor after curative resection of colorectal Cancer. Ann Surg Oncol. 2015;22(8):2663-8. https://doi.org/10. 1245/s10434-014-4281-6 PubMed PMID: 25564158.

15. Amini N, Spolverato G, Gupta R, Margonis GA, Kim Y, Wagner D, et al. Impact Total psoas volume on short- and long-term outcomes in patients undergoing curative resection for pancreatic adenocarcinoma: a new tool to assess sarcopenia. J Gastrointest Surg. 2015;19(9):1593-602. https://doi. org/10.1007/s11605-015-2835-y PubMed PMID: 25925237.

16. Tan $B H$, Birdsell $L A$, Martin L, Baracos VE, Fearon KC. Sarcopenia in an overweight or obese patient is an adverse prognostic factor in pancreatic cancer. Clin Cancer Res. 2009;15(22):6973-9. https://doi.org/10.1158/10780432.Ccr-09-1525 PubMed PMID: 19887488.

17. Japanese Gastric Cancer A. Japanese classification of Gastric carcinoma 2nd English edition. Gastric Cancer. 1998;1(1):10-24 PubMed PMID: 11957040

18. Xie JW, Lu J, Wang JB, Lin JX, Chen QY, Cao LL, et al. Prognostic factors for survival after curative resection of gastric mixed adenoneuroendocrine carcinoma: a series of 80 patients. BMC Cancer. 2018;18(1):1021. https://doi. org/10.1186/s12885-018-4943-z PubMed PMID: 30348122.

19. Dello SA, Lodewick TM, van Dam RM, Reisinger KW, van den Broek MA, von Meyenfeldt MF, et al. Sarcopenia negatively affects preoperative total functional liver volume in patients undergoing liver resection. HPB. 2013; 15(3):165-9. https://doi.org/10.1111/j.1477-2574.2012.00517.x PubMed PMID: 23020663.

20. Mitsiopoulos N, Baumgartner RN, Heymsfield SB, Lyons W, Gallagher D, Ross R. Cadaver validation of skeletal muscle measurement by magnetic resonance imaging and computerized tomography. J Appl Physiol (Bethesda, Md: 1985). 1998;85(1):115-22 PubMed PMID: 9655763.

21. Prado CM, Lieffers JR, McCargar $L$, Reiman T, Sawyer MB, Martin L, et al. Prevalence and clinical implications of sarcopenic obesity in patients with solid tumours of the respiratory and gastrointestinal tracts: a populationbased study. Lancet Oncol. 2008;9(7):629-35. https://doi.org/10.1016/s14702045(08)70153-0 PubMed PMID: 18539529

22. Dindo D, Demartines N, Clavien PA. Classification of surgical complications: a new proposal with evaluation in a cohort of 6336 patients and results of a survey. Ann Surg. 2004;240(2):205-13 PubMed PMID: 15273542.

23. Welin S, Sorbye H, Sebjornsen S, Knappskog S, Busch C, Oberg K. Clinical effect of temozolomide-based chemotherapy in poorly differentiated endocrine carcinoma after progression on first-line chemotherapy. Cancer. 2011;117(20):4617-22. https://doi.org/10.1002/cncr.26124 PubMed PMID: 21456005.

24. Keats AS. The ASA classification of physical status--a recapitulation. Anesthesiology. 1978;49(4):233-6 PubMed PMID: 697075.

25. Owens WD, Felts JA, Spitznagel EL. ASA physical status classifications: a study of consistency of ratings. Anesthesiology. 1978;49(4):239-43 PubMed PMID: 697077

26. Camp RL, Dolled-Filhart M, Rimm DL. X-tile: a new bio-informatics tool for biomarker assessment and outcome-based cut-point optimization. Clin Cancer Res. 2004;10(21):7252-9 PubMed PMID: 15534099.

27. Martin L, Birdsell L, Macdonald N, Reiman T, Clandinin MT, McCargar $\sqcup$, et al. Cancer cachexia in the age of obesity: skeletal muscle depletion is a powerful prognostic factor, independent of body mass index. J Clin Oncol. 2013;31(12):1539-47. https://doi.org/10.1200/jco.2012.45.2722 PubMed PMID: 23530101.

28. Cives M, Strosberg JR. Gastroenteropancreatic neuroendocrine tumors. CA Cancer J Clin. 2018;68(6):471-87. https://doi.org/10.3322/caac.21493 PubMed PMID: 30295930

29. Fielding RA, Vellas B, Evans WJ, Bhasin S, Morley JE, Newman AB, et al. Sarcopenia: an undiagnosed condition in older adults. Current consensus definition: prevalence, etiology, and consequences. International working group on sarcopenia. J Am Med Dir Assoc. 2011;12(4):249-56. https://doi. org/10.1016/j.jamda.2011.01.003 PubMed PMID: 21527165.

30. Cruz-Jentoft AJ, Baeyens JP, Bauer JM, Boirie Y, Cederholm T, Landi F, et al. Sarcopenia: European consensus on definition and diagnosis: report of the European working group on sarcopenia in older people. Age Ageing. 2010;
39(4):412-23. https://doi.org/10.1093/ageing/afq034 PubMed PMID: 20392703.

31. Chen L-K, Liu L-K, Woo J, Assantachai P, Auyeung T-W, Bahyah KS, et al. Sarcopenia in Asia: consensus report of the Asian Working Group for Sarcopenia. J Am Med Dir Assoc. 2014;15(2). https://doi.org/10.1016/j.jamda. 2013.11.025 PubMed PMID: 24461239.

32. Simonsen C, de Heer P, Bjerre ED, Suetta C, Hojman P, Pedersen BK, et al. Sarcopenia and postoperative complication risk in gastrointestinal surgical oncology: a meta-analysis. Ann Surg. 2018;268(1):58-69. https://doi.org/10. 1097/SLA.0000000000002679 Epub 2018/01/27, PubMed PMID: 29373365.

33. Öberg K, Knigge U, Kwekkeboom D, Perren A. Neuroendocrine gastroentero-pancreatic tumors: ESMO Clinical Practice Guidelines for diagnosis, treatment and follow-up. Ann Oncol. 2012;23(Suppl 7):vii124-vii30 PubMed PMID: 22997445

34. Tegels JJ, van Vugt JL, Reisinger KW, Hulsewé KW, Hoofwijk AG, Derikx JP, et al. Sarcopenia is highly prevalent in patients undergoing surgery for gastric cancer but not associated with worse outcomes. J Surg Oncol. 2015; 112(4):403-7. https://doi.org/10.1002/jso.24015 PubMed PMID: 26331988.

35. Pecorelli N, Carrara G, De Cobelli F, Cristel G, Damascelli A, Balzano G, et al. Effect of sarcopenia and visceral obesity on mortality and pancreatic fistula following pancreatic cancer surgery. Br J Surg. 2016;103(4):434-42. https:// doi.org/10.1002/bjs.10063 PubMed PMID: 26780231.

36. Ouchi A, Asano M, Aono K, Watanabe T, Oya S. Laparoscopic colorectal resection in patients with sarcopenia: a retrospective case-control study. J Laparoendosc Adv Surg Tech A. 2016;26(5):366-70. https://doi.org/10.1089/ lap.2015.0494 PubMed PMID: 26982506

37. Modlin IM, Oberg K, Chung DC, Jensen RT, de Herder WW, Thakker RV, et al. Gastroenteropancreatic neuroendocrine tumours. Lancet Oncol. 2008;9(1): 61-72. https://doi.org/10.1016/s1470-2045(07)70410-2 PubMed PMID: 18177818.

38. Pericleous M, Toumpanakis C, Lumgair H, Caplin ME, Morgan-Rowe L, Clark I, et al. Gastric mixed adenoneuroendocrine carcinoma with a trilineage cell differentiation: case report and review of the literature. Case Rep Oncol. 2012;5(2):313-9. https://doi.org/10.1159/000339611 PubMed PMID: 22740822

39. Kim TY, Chae HD. Composite neuroendocrine carcinoma with adenocarcinoma of the stomach misdiagnosed as a giant submucosal tumor. J Gastric Cancer. 2011;11(2):126-30. https://doi.org/10.5230/jgc.2011. 11.2.126 PubMed PMID: 22076214.

40. Fernandes D, Soares JB, Rolanda C. Gastric mixed Adenoneuroendocrine carcinoma. GE Portuguese J Gastroenterol. 2015;22(1):34-6. https://doi.org/ 10.1016/j.jpge.2014.07.003 PubMed PMID: 28868368.

\section{Publisher's Note}

Springer Nature remains neutral with regard to jurisdictional claims in published maps and institutional affiliations.

\section{Ready to submit your research? Choose BMC and benefit from:}

- fast, convenient online submission

- thorough peer review by experienced researchers in your field

- rapid publication on acceptance

- support for research data, including large and complex data types

- gold Open Access which fosters wider collaboration and increased citations

- maximum visibility for your research: over $100 \mathrm{M}$ website views per year

At BMC, research is always in progress.

Learn more biomedcentral.com/submissions 